\title{
Off-flavor por geosmina e 2-Metilisoborneol na aquicultura
}

\section{Off-flavor by geosmine and 2-methylisoborneol in aquaculture}

\author{
Silvia Maria Guimarães de Souza ${ }^{1 *}$; Vinicius Dias Mathies²; \\ Renata Facchin Fioravanzo ${ }^{2}$
}

\section{Resumo}

\begin{abstract}
A aquicultura entra numa nova era nas últimas décadas, em que os sistemas extensivos tradicionais estão sendo substituídos por criações intensivas e tecnificadas. No intuito de auferir maior lucratividade, a qualidade do pescado tem sido relegada a segundo plano, fato que gera ou agrava problemas antes toleráveis, a exemplo do off-flavor. Assim, a presente revisão tem por objetivo esclarecer, de forma sucinta, o problema do off-flavor na aquicultura, bem como apontar as soluções atuais e as perspectivas futuras para reverter a situação que se apresenta.
\end{abstract}

Palavras-chave: Off-flavor, geosmina, cianobactérias, actinomicetos, MIB

\begin{abstract}
The aquaculture has reached a new age, in which traditional extensive systems are being substituted by technology-intensive aquaculture systems. In order to achieve higher yields, aspects of fish quality have been neglected, a fact that causes or aggravates hitherto tolerable problems, such as off-flavor. The main purpose of this review is to clarify, briefly, the problem of off-flavor in aquaculture, as well as put forward present solutions and future perspectives.
\end{abstract}

Key words: Off-flavor, geosmin, cyanobacteria, actinomycetes, MIB

\footnotetext{
${ }^{1}$ Prof $^{\mathrm{a}}$. Associado II do Dept ${ }^{\mathrm{o}}$ de Zootecnia, Faculdade de Agronomia, Universidade Federal do Rio Grande do Sul, UFRGS, Porto Alegre, RS. E-mail: silsouza@ufrgs.br

${ }^{2}$ Discentes de Medicina Veterinária, UFRGS, Porto Alegre, RS. E-mail: E-mail: viniciusmathies@yahoo.com.br; refioravanzo@ hotmail.com

* Autor para correspondência
} 


\section{Introdução}

A aquicultura é uma das atividades zootécnicas que mais tem se expandido nas últimas décadas. Paralelamente aos constantes avanços técnicos e incrementos na produção, surgem novos desafios. Entre esses, a presença de sabores indesejáveis no pescado tem recebido pouca atenção dos pesquisadores no Brasil. Descritos como uma inabilidade em controlar a qualidade do ambiente de cultivo, esses sabores/odores são comumente chamados de "off-flavor" ou OF (TUCKER, 2000; MARTIN; IZAGUIRRE; WATERSTRAT, 1991).

Conjuntamente com manejos insatisfatórios no cultivo, o OF desponta como um problema que causa perdas milionárias em países como Estados Unidos e França, conhecidos por sua criação tecnificada em aquicultura (BIATO, 2005). A presença de OF pode causar uma grande redução no consumo de pescado cultivado. (BIATO, 2005; VALLOD et al., 2007).

A habilidade de detectar gostos e odores desagradáveis tem fundamental importância para a sobrevivência dos animais, pois permite que esses percebam potenciais perigos no alimento antes de ingeri-los (DIONIGI, 1993).

Parâmetros químicos, físicos e biológicos determinam a qualidade de água nos viveiros de cultivo (KUBITZA, 2003) e, com a expansão das indústrias e da urbanização, o ambiente límnico vem sofrendo ao longo do tempo profundas alterações. Essas trazem como conseqüência a alteração da comunidade aquática e geram a hiperprodução de duas substâncias que são as principais causas de OF em aquicultura: Geosmina e 2-metilisoborneol ou MIB.

A geosmina e o MIB são compostos responsáveis, respectivamente, pelo cheiro de terra e bolor ou mofo na água. A presença desses compostos orgânicos deve-se principalmente à proliferação de cianobactérias em mananciais com altos e desequilibrados níveis de nutrientes, fundamentalmente resultantes de eutrofização. Esta, por sua vez, é provocada por falta de chuva, calor, poluição, esgotos domésticos e agrotóxicos. Provavelmente a primeira citação de odor e sabor indesejáveis em peixes foi apresentada em encontro técnico da FAO (IREDALE; RIGBY, 1972). Já naquela época, o florescimento excessivo de algas azuis (hoje cianobactérias) e actinomicetos em água doce era apontado como uma de suas possíveis causas. Com o passar dos anos, os problemas relacionados ao $\mathrm{OF}$ só têm se agravado. No ano de 2000, somente a indústria de "catfish" nos EUA contabilizou prejuízos anuais de U\$ 50 milhões (KUBITZA, 2000). Outros países, como a França, referem o problema em fazendas de truta, (ROBIN et al., 2006). Mais recentemente, em Israel, Guttman e Rijn (2008), mostraram a presença de OF, pela primeira vez, em cultivo de tilápias (Oreochromis niloticus) com sistemas de recirculação. Com esta mesma espécie e sistema de cultivo, com e sem circulação, autores observaram que houve muita variação entre as notas dadas para o sabor alterado denominado (global OF), sendo este maior que outros tipos de sabores e odores como mofo, água servida, químico, madeira, gramas, ocre, ácidos, azedos e amargos. Entretanto, não houve diferença significativa entre os dois sistemas de cultivo. (SOUZA et al., 2000).

O objetivo do presente trabalho é apresentar uma revisão dos principais fatores predisponentes e/ou determinantes da presença de OF em pescado cultivado e as perspectivas futuras para a solução desse impasse.

\section{Definição de off-flavor}

As substâncias que possuem baixa toxicidade para os animais e os humanos são, de um modo geral, aquelas mais frequentemente envolvidas na produção de OF (DIONIGI, 1993).

Os fatores biológicos da presença de OF são prevalentes na aquicultura, entretanto deve-se considerar que existem outros fatores que afetam tanto a qualidade do pescado quanto da água para consumo humano e animal. Fatores não biológicos 
referem-se aos sabores e odores familiares, como gosto de capim, gosto de madeira entre outros. As causas químicas desses tipos de $\mathrm{OF}$ ainda não foram identificadas. A descriminação de um sabor é uma percepção individual, que pode variar de pessoa para pessoa, resultando no uso de expressões diferentes para uma mesma sensação.

Nesse sentido, é importante a padronização da terminologia referente a $\mathrm{OF}$, para que tanto pesquisadores quanto serviços de controle de qualidade das indústrias, possam utilizar a mesma nomenclatura. (TUCKER, 2000).

O gosto de terra e mofo é causado pela presença de geosmina e do 2-metilisoborneol no ambiente aquático. Essas substâncias são produzidas por elevadas populações de cianobactérias e actinomicetos, sendo então absorvidas por difusão pelos tecidos dos peixes. Os principais gêneros das primeiras são os seguintes: Microcystis, Anabaena, Aphanizomenon, Planktothrix e Oscilatoria. Quanto aos actinomicetos, destacamse: Actinoplanes, Micromonospora, Rhodococcus, Streptomyces, Thermoactinomyc e Nodularia (BIATO, 2005; PERSSON, 1995). Trabalhando em tanques de cultivo em Beijing (China), Xu et al. (2010) observaram que as microalgas Melosira spp. e Cyclotella spp foram as maiores causadoras de OF nos sistemas intensivos de cultivo de água doce, no período de verão e outono, enquanto que o Euglenophyta e outras algas apresentaram uma menor influência no efeito de OF. Para mais detalhes, ver Tabelas 1 e 2 .

Tabela 1. Principais cianobactérias potencialmente causadores de OF.

\begin{tabular}{|c|c|c|c|c|}
\hline $\begin{array}{c}\text { Tipo de } \\
\text { organismo }\end{array}$ & País & Gêneros & $\begin{array}{l}\text { Metabólitos de } \\
\text { OF } \\
\end{array}$ & Referências \\
\hline \multirow[t]{10}{*}{ Cianobactérias } & EUA & Oscillatoria & 2-MIB & $\begin{array}{l}\text { Olson, Weirich e Grimm, 2001; } \\
\text { Tucker, 2000; Schrader et al., 1988; } \\
\text { Van der Ploeg, Dennis e De Regt, } \\
\text { 1995; Van der Ploeg e Tucker, 1993; } \\
\text { Martin et al., 1987; Lovell, } 1983\end{array}$ \\
\hline & Noruega & & Geosmina & $\begin{array}{l}\text { Berglind et al., 1983; Utkilen e } \\
\text { Froeshaug, } 1992\end{array}$ \\
\hline & $\begin{array}{l}\text { EUA } \\
\text { Japão }\end{array}$ & & 2-MIB & $\begin{array}{l}\text { Hoson, 1992; Negoro; Ando e } \\
\text { Ichikawa, 1988; Izaguirre et al., } 1983\end{array}$ \\
\hline & Japão & & 2-MIB/ Geosmina & Matsumoto e Tsuchiya, 1988 \\
\hline & EUA & & 2-MIB & Bafford et al., 1992 \\
\hline & EUA & & & Schrader e Blevinset, 1993 \\
\hline & $\begin{array}{l}\text { Tailândia, } \\
\text { EUA }\end{array}$ & Anabaena & Geosmina & $\begin{array}{l}\text { Wu, Ma e Chou 1991; Van der Ploeg, } \\
\text { Tucker e Boyd, 1992; Lelana, 1987; } \\
\text { Lovell et al., } 1986\end{array}$ \\
\hline & Japão & & & $\begin{array}{l}\text { Tsuchiya e Matsumoto, 1988; } \\
\text { Aoyama et al., } 1991\end{array}$ \\
\hline & $\begin{array}{l}\text { EUA } \\
\text { Austrália }\end{array}$ & & & $\begin{array}{l}\text { Bowmer et al., 1992; Rosen, Mcleod } \\
\text { e Simpson, } 1992\end{array}$ \\
\hline & Europa & Aphanizomenon & Geosmina & Jüttner, Hoeflacher e Wurster, 1986 \\
\hline
\end{tabular}

Fonte: Modificada de Robin et al. (2006). 
Tabela 2. Principais actinomicetos potencialmente causadores de OF.

\begin{tabular}{|c|c|c|c|c|}
\hline Actinomicetos & EUA & Streptomyces & $\begin{array}{l}\text { Geosmina/ } \\
\text { MIB }\end{array}$ & Gerber, 1979 \\
\hline & \multirow[t]{2}{*}{ EUA } & & IPMB & \\
\hline & & & MIB & Sugiura, et al., 1994 \\
\hline & Japão & & Geosmina & Schrader e Blevins, 1993 \\
\hline & EUA & & & Wood, Williams e White, 1985 \\
\hline & GBR & & & Dionigi e Champagne, 1995 \\
\hline & EUA & & & Lind e Katzif, 1988 \\
\hline & Japão & & Geosmina/MIB & Tsuchiya, Matsumoto e Okamoto, 1978 \\
\hline
\end{tabular}

Fonte: Modificada de Robin et al. (2006).

Embora possamos creditar às cianobactérias a maioria dos casos de $\mathrm{OF}$, os actinomicetos não devem ser subestimados, pois, diferentemente das cianobactérias, eles são capazes de produzir a geosmina e o MIB concomitantemente, além de outros compostos odoríferos como norbornanol, metiloxipinazina, dimetil sulfito e metileptenona (ZAITLINA; WATSON, 2006).

\section{O que são a Geosmina e o MIB?}

Geosmina é um álcool terciário bicíclico que apresenta odor de terra mesmo em soluções aquosas muito diluídas e pode ser encontrada naturalmente em beterrabas e em algumas raízes de plantas. O 2-metilisoborneol ou MIB também pertence à mesma categoria química da geosmina. Ambos são citados por Guttman e Rijn (2008) como compostos terpenóides semivoláteis, sendo altamente odoríferos na água ou nos peixes.

A biosíntese de geosmina e MIB por microrganismos ocorre por duas vias metabólicas comuns: a do ácido mevalônico (MEV) e a da deoxixilulose (DOXP/MEP) (WANKE; SKORUPINSKA-TUDEK; SWIEZEWSKA, 2001). Em culturas in vitro, a perda da capacidade de produção de geosmina e MIB indica que a produção dessas deve ser induzida e mantida por algum fator externo. Sob condições ideais, as cepas criadas em laboratório perderam os genes responsáveis por meio da mutação. O gene responsável pela geosmina em Streptomyces coelicolor localiza-se no cyc2, o mesmo utilizado na produção de ácido mevalônico, evidenciando a íntima relação entre as duas substâncias (GUST, 2003). Por algum tempo, essas substâncias foram consideradas apenas produtos secundários de rotas metabólicas, mas as últimas pesquisas já apontam para moléculas de sincronização servindo como gatilho para que todas as células de uma colônia iniciem a reprodução quando em ambiente favorável (LAZDUNSKI; VENTRE; STURGIS, 2004). Outros ainda afirmam que possuem efeito inibitório sobre outras algas, atuando como inibidor competitivo e sendo até tóxico em alguns casos (WATSON; RIDAL, 2004).

Até hoje, não há registro de intoxicação em pessoas por geosmina ou MIB, pois, aparentemente, a dose tóxica para humanos é muito superior à dose letal em peixes. No entanto não podemos ignorar que todos os gêneros produtores de geosmina e MIB apresentadas aqui possuem espécies produtoras de toxinas, como microcistinas e nodularinas, altamente hepatotóxicas. De uma forma geral, a presença de OF na água indica floração excessiva de cianobactérias e, consequentemente, a presença de cianotoxinas, mas sua ausência não significa que as microalgas não estejam presentes. (FALCONER et al., 1999).

O episódio de Caruaru, no estado de Pernambuco em 1996, onde houve a morte de pacientes por 
presença de cianotoxinas na água durante diálise, ressaltou a importância da regulamentação da presença daquelas toxinas na água potável e do controle das cianobactérias no manancial (Portaria 518 do Ministério da Saúde de 25 de março de 2004 (CYBIS et al., 2006).

\section{Determinação Sensorial e Instrumental de OF}

\section{Análise sensorial}

A detecção de OF, por análises sensoriais, é realizada de acordo com a metodologia para Avaliações Sensoriais Gerais de Comidas, as quais são descritas na ISO 13301 (INTERNATIONAL ORGANIZATION FOR STANDARDIZATION, 2002). Constitui-se de um painel com testadores profissionais. Outra maneira de avaliação é através da utilização de consumidores comuns, previamente treinados para este fim, com a seleção daqueles mais sensíveis. Estas duas maneiras permitem a realização dos testes com segurança, uma vez que a grande maioria dos consumidores são menos sensíveis do que o júri selecionado (HOWGATE, 2004).

A sensibilidade humana para a geosmina pode variar muito, mas, segundo Butteryet al. (1976), se aceita que o limiar de detecção seja em torno de 0,02 $\mu \mathrm{g} / \mathrm{L}$ na água e de $6 \mu \mathrm{g} / \mathrm{kg}$ na truta (YURKOWSKI; TABACHEK, 1974). Já para o MIB, o limiar de detecção para humanos é em torno de $0,04 \mu \mathrm{g} / \mathrm{L}$ na água, de acordo com Persson (1979), e de 0,6 $\mu \mathrm{g} / \mathrm{kg}$ em peixes (JOHNSEN; KELLY, 1990). Sendo que Tucker (2000) afirma que em filés de "catfish" é de $0,7 \mu \mathrm{g} / \mathrm{kg}$.

De acordo com Grimm, Lloyd e Zimba (2004), os métodos de avaliação sensoriais empregados em pescado, para determinação de $\mathrm{OF}$, têm variado de acordo com os avaliadores, uma vez que alguns preferem utilizar a musculatura próxima à cauda, enquanto outros usam a musculatura próxima às vísceras. Estes autores utilizaram pequenos pedaços de filé de peixe preparados em microondas, os quais eram cheirados para uma detecção mais grosseira de odores.

Alguns pontos críticos da análise sensorial vêm sendo estudados. Gautier, Boyd e Lovell (2002), avaliando o tamanho da amostragem para avaliação de OF, concluiu que 30 exemplares são geralmente necessários para limitar a variação que ocorre em um mesmo tanque de cultivo. Na prática, entretanto, os processadores de peixe no sudeste dos Estados Unidos tentam garantir a consistência na qualidade do "catfish" cultivado pelos testes sensoriais, antes da despesca e do processamento. Normalmente os produtores submetem uma amostra de peixe à planta de processamento uma semana antes da data da despesca (TUCKER, 2000).

O método mais comumente utilizado é a lavagem da amostra e o cozimento em forno de microondas, sendo a seguir cheirado e saboreado por testadores profissionais. Se o peixe é considerado aceitável, a população do tanque em questão é provisoriamente aprovada para a compra, e a despesca é agendada. Outra amostra é testada um dia antes da despesca e, esta é cancelada se OF for detectado. Um teste final é feito de um animal escolhido diretamente do caminhão de transporte e, se o resultado for positivo para o $\mathrm{OF}$, todos os animais retornam para o criador, sendo a compra cancelada.

Hoje em dia, os resultados da avaliação sensorial são confrontados com análises de concentração de compostos voláteis na carne, na pele e no fígado do pescado. Algumas correlações feitas entre essas duas técnicas estão sendo utilizadas para definir o exato limiar da sensibilidade humana para OF em peixes. A definição exata de um valor limiar para esses compostos torna-se difícil, considerando a diversidade de protocolos (ROBIN et al., 2006). Parâmetros como tamanho do peixe, temperatura da água e concentração lipídica na carne não são levados em consideração (HOWGATE, 2004). Mais recentemente, Percival, Drabsch e Glencross (2008) constataram que existe uma alta correlação 
entre a presença de OF e o nível de lipídios em filés de peixes maiores $(2000 \mathrm{~g})$ e menores $(400 \mathrm{~g}) \mathrm{de}$ barramundi (Lates calcarifer) criados em fazendas na Austrália.

\section{Análise instrumental}

Embora o olfato e o paladar humano possam detectar rapidamente o MIB e a geosmina presentes em concentrações muito baixas, somente dados semiquantitativos são adquiridos, e o poder de detecção humana é sobrecarregado rapidamente, levando a uma perda de sensibilidade (GRIMM; LLOYD; ZIMBA, 2004).

A análise instrumental necessária para detectar baixas concentrações dos compostos em grandes amostragens torna muitos métodos, senão a maioria, impraticáveis devido aos altos custos dos equipamentos e à necessidade de operadores treinados (GRIMM; LLOYD; ZIMBA, 2004). Um dos testes analíticos utilizados, para fins de pesquisa, é a "solid-phase microextraction technology" ou tecnologia de microextração em fase sólida (SPME). Porém, segundo Grimm, Lloyd e Zimba (2004), a SPME não é um meio efetivo de extração para compostos de amostras de matrizes complexas como solo e tecidos musculares. Ligações físicas permitem a aderência dos compostos às matrizes da amostra e este problema poderia ser resolvido com o uso de destilação por microondas (CONTE et al., 1996; LLOYD; GRIMM, 1999). Esta técnica promove a liberação destes compostos no vapor efluente que, após a coleta pela condensação, poderia ser utilizado prontamente para o SPME.

Outra técnica amplamente empregada é o uso de cromatografia gasosa e espectrofotometria de massa, com capacidade de analisar os compostos com uma sensibilidade de $30 \mathrm{ppm}$ para o MIB e 20 ppt para a geosmina. Grimm, Lloyd e Zimba (2004) citam que a vantagem desta técnica em relação ao SPME é a rapidez no processamento das amostras: enquanto a técnica do SPME é realizada em 25 min, a análise por cromatografia gasosa e espectrofotometria de massa ocorre em 15 min. Dessa forma, 50 a 70 peixes poderiam ser analisados automaticamente, por dia e por um único operador.

Para a avaliação dessas tecnologias, um estudo comparativo entre o método instrumental (cromatografia gasosa e espectrofotometria de massa) e o método sensorial foi realizado por Grimm, Lloyd e Zimba (2004) com o objetivo de determinar os limites para os provadores e relatar a similaridade de resultados para os OF, em "catfish". Os resultados desse estudo apontam a geosmina com um limiar de detecção sensorial semelhante ao MIB, relativamente à ordem de magnitude da diferença relatada na literatura. O limiar determinado de detecção de OF por provadores variou entre 0,1 e $0,2 \mu \mathrm{g} / \mathrm{kg}$ para o MIB e entre 0,25 e $0,5 \mu \mathrm{g} / \mathrm{kg}$ para a geosmina. Assim, os limites máximos de $0,1 \mu \mathrm{g} /$ $\mathrm{kg}$ e $0,25 \mu \mathrm{g} / \mathrm{kg}$ foram determinados como sendo pontos de corte para a aceitação do produto por meios analíticos instrumentais.

\section{Absorção e eliminação de Geosmina e MIB (2-metilisoborneol) pelos organismos aquáticos}

Os peixes podem adquirir OF pela ingestão de cianobactérias contendo reservas intracelulares. A rota principal de absorção é o transporte passivo dos compostos presentes na água (FROM; HORLYCK, 1984). As brânquias são o sítio primário de absorção, pela sua estrutura e função, aumentando a difusão de geosmina e de MIB entre a água e o sangue (TUCKER, 2000). Essas substâncias são inicialmente transportadas para os tecidos de maior suprimento sanguíneo e, depois, redistribuídas pelos tecidos ricos em gordura (JOHNSEN; LLOYD, 1992).

A eliminação da geosmina e as mudanças relacionadas com a intensidade do OF foram estudadas por Lelana (1987). Em água isenta de geosmina, o autor introduziu peixes com concentração inicial de $90 \mu \mathrm{g} / \mathrm{kg}$ e verificou a necessidade de um período de seis dias para que as concentrações decaíssem abaixo de $8 \mu \mathrm{g} / \mathrm{kg}$, 
considerado o nível sensorial limite para humanos. Diversos autores avaliam que a velocidade de eliminação desses produtos é variável entre as espécies de peixes. Desse modo, espécies de águas frias, como salmonídeos, depurariam os compostos mais lentamente. Quando utilizadas as melhores condições de depuração (peixes magros e águas mornas), os níveis aceitáveis de compostos são atingidos em menos de $60 \mathrm{~h}$ (TUCKER, 2000).

\section{Fatores predisponentes ao aparecimento de OF em aquicultura}

Actinomicetos, cianobactérias e fungos existem normalmente em qualquer corpo de água doce, mas a concentração deles é baixa, pois predominam as algas verdes. $\mathrm{Na}$ aquicultura, as principais causas do desenvolvimento excessivo daqueles organismos são os seguintes: (a) baixa relação entre nitrogênio e fósforo, Pearl e Tucker (1995), resultantes da excessiva quantidade de fósforo na água de cultivo - o que decorre, entre outras razões, tanto da elevada taxa alimentar, pelo uso de alimentadores automáticos, Robin et al. (2006), e/ou rações formuladas de modo a liberar muito $\mathrm{P}$, como do uso abusivo de fertilizantes fosfatados solúveis e/ou adubo orgânico, Tucker (2000); (b) longos períodos de muita luz solar associada à altas temperaturas e períodos de poucas chuvas e ventos, Turchini et al. (2007); (c) alta densidade de animais nos cultivos; (d) escassa renovação de água; (e) eliminação dos predadores naturais de cianobactérias, como alguns rotíferos e microcrustáceos, pelo uso indevido de inseticidas (antiparasitários) e outros agrotóxicos (YU; SOUZA, 2007; MABÍLIA; SOUZA, 2006).

\section{Impacto Econômico}

Não foram encontrados trabalhos específicos publicados sobre impacto econômico do $\mathrm{OF}$ no Brasil, de forma que a maioria dos dados apresentados aqui é da indústria do "catfish" nos EUA. A maior prevalência ocorre no verão, em que a estatística indica que mais da metade dos cultivos apresentam peixes com níveis de OF acima do tolerável (DIONIGI; BETT, 1998). Devido ao mercado consumidor exigente, os piscicultores americanos contratam técnicos treinados para provar e detectar níveis de OF nos peixes em cada criadouro. Uma vez reprovados na prova, todos os peixes do criadouro estarão inaceitáveis para comercialização até a resolução do problema. Tal processo atrasa o tempo de criação e abate, bem como interrompe o cronograma normal de fornecimento para o mercado. Peixes com OF geralmente são encaminhados para depuração, originando custos por atraso de entrega, por alimentação extra e por ocupação do espaço físico que poderia ser destinado a uma nova remessa de alevinos. Em 1995, tal custo produzido segundo Engle, Pounds e van der Ploeg (1995), o OF representa 3\% a 16\% do custo operacional ou U\$ 10 a 60 milhões por ano. Fora isso, ainda há riscos de perda por estresse devido à manipulação, por doenças durante a depuração ou por deterioração da água. Para acompanhar as exigências crescentes do mercado consumidor, o OF no pescado cultivado, a curto e a médio prazo, será uma das principais causas de perdas econômicas dos aquicultores em qualquer país (ROBIN et al., 2006).

Em trabalho sobre cianobactérias e metabólitos bioativos, Smith, Boyer e Zimba (2008) afirmam que está claro que o suprimento de alimento oriundo da aquicultura é crítico para atender às demandas da população mundial em expansão. $\mathrm{O}$ crescimento da indústria da aquicultura será contínuo e requer o desenvolvimento de uma linhagem de peixe geneticamente superior capaz de sobreviver e crescer rapidamente sob condições sub-ótimas dos tanques de cultivo, e desenvolver tecnologias para controlar o incômodo do desenvolvimento de espécies de microalgas causadoras de OF. 


\section{Manejo e medidas de controle do OF na aquicultura}

Provavelmente a melhor forma de controle de OF é a prevenção, entretanto não será simples a sua implementação, uma vez que incluem práticas de controles químicos, físicos e biológicos somente obtidas em ações multidisciplinares.

\section{Medidas Químicas de Controle}

Uma vez que a presença de geosmina e MIB está intimamente ligada à floração de cianobactérias e actinomicetos, a remediação lógica seria o uso de algicidas, desaconselhado devido à poluição gerada e à baixa seletividade. Os algicidas utilizados comumente são compostos como sais de ferro ou cobre, acetato de fentina, endotal, quinoclamina, cloretos, brometos de alquilbenzilamônio, hipocloreto de cálcio, hipoclorito de sódio e diclorofena. Entre os algicidas mais utilizados estão os derivados de cobre, sendo que nos EUA, estes são os únicos aprovados para uso em aquicultura. $\mathrm{O}$ íon cobre, em alta concentração, inibe a respiração, a fotossíntese e a divisão celular, por impedir a síntese de clorofila (PRICE; MOREL, 1994). O maior problema de sua aplicação é que, apesar de ser mais seletivo que outras opções, ainda é muito tóxico para outros organismos bentônicos e plantas aquáticas. Outro ponto negativo no uso de algicidas é a hiper liberação de geosmina e de MIB na água, logo após a aplicação dos mesmos, devido a extravasamento do conteúdo celular, em face de ruptura das membranas, provocando um aumento instantâneo da concentração das toxinas na água.

Uma medida química de eliminar o OF, ainda restrita à água potável, é neutralizando as moléculas responsáveis, através da queração ou oxidação por ozônio, os quais podem eliminar quase completamente a presença de geosmina e de MIB, por conferir polaridade as suas moléculas e conseqüente aumento de pressão de vapor (PARK et al., 2007).

\section{Medidas físicas de controle}

As medidas físicas são menos onerosas e de execução relativamente simples, sendo aplicáveis tanto à aquicultura quanto às companhias de fornecimento de água para consumo humano. Dentre elas se podem destacar a filtração, a decantação, Aiub (2006), o controle de temperatura, a sonicação e os raios UV. A filtração é a simples passagem da água, forçada ou não, através de algum material filtrante. As mais utilizadas são pó de ossos e carvão ativado, ambos com propósito de adsorver as moléculas de geosmina e MIB sob sua superfície. Já o controle de temperatura é somente aplicado em aquicultura devido à extensão do corpo de água a ser tratado. Geralmente se usa cobertura física como lonas ou redes sob açudes para bloquear o raio solar, ou ventilação artificial para impedir o aquecimento. O uso de raios UV tem o mesmo objetivo de algicidas, ou seja, eliminação de microrganismos causadores de off-flavor. Os raios UV geram erros no pareamento de DNA e transcrição, além de produzirem radicais livres. Já a sonicação é o procedimento que utiliza a energia das ondas sonoras, mais comumente o ultra-som, para auxiliar no processo de agitação das partículas; pode ser usada para acelerar a dissolução de determinadas substâncias em um solvente, prover a energia de ativação necessária para que uma reação química ocorra e, em aplicações biológicas, pode romper ou desativar vários materiais orgânicos. A alta eficiência desta técnica se deve ao fato do ultrasom ser capaz de eliminar compostos odoríferos mesmo em concentrações baixas (SONG, 2007).

\section{Medidas biológicas de controle}

A geosmina e o MIB, segundo Tucker (2000), são naturalmente degradadas na água. Nos peixes, são acumuladas e eliminadas da mesma forma, isto é, por difusão passiva. A diferença principal é que o acúmulo acontece em uma velocidade muito superior. Assim, uma das técnicas mais aplicadas na aquicultura para a eliminação de OF é a depuração, 
que consiste em fazer os peixes passarem um determinado período, antes do abate, em sistemas de água corrente e sob regime de restrição alimentar. A eliminação de OF na depuração depende da espécie, pois peixes com maior teor de gordura tendem a absorver mais geosmina e MIB, pelo fato destes serem apolares. A depuração de tilápias do Nilo criadas na represa de Ibitinga, no rio Tietê-SP, levou nove dias para atingir os níveis aceitáveis para consumo (TORLONI, 1983). Para algumas espécies de carpa, este tempo pode atingir até 20 dias. Embora seja uma das técnicas paliativas mais simples, ela não impediu prejuízos econômicos causados: pelo atraso de cronograma, pela redução de crescimento, pela baixa eficiência alimentar, pelo aumento de mortalidade dos peixes, pela ampliação da infra-estrutura necessária e pela possibilidade de ocorrência de doenças durante a depuração (BIATO, 2005). Outra forma de controle biológico, conhecida como pousio, consiste em secagem e exposição do leito de tanques e viveiros ao sol por algumas semanas, matando organismos aquáticos indesejáveis (BOYD, 1981). Com a crescente preocupação com a qualidade do efluente da aquicultura, ganha importância o uso de filtros biológicos. Estes, conhecidos há mais de dois séculos, usam, em sua maioria, microrganismos para remover a amônia. O filtro biológico é um dos componentes dos sistemas de recirculação, sendo sugerido adicionar a este sistema uma fase de condições anaeróbicas, minimizando assim o aparecimento dos actinomicetos, produtores de MIB e geosmina. (GUTTMAN; RIJN, 2008).

\section{Considerações finais}

Tendo em vista que o OF está diretamente ligado à qualidade da água, a melhor forma de eliminá-lo seria diminuindo a eutrofização do ambiente de cultivo o que exige grandes esforços tecnológicos e econômicos. As boas práticas de manejo, a diminuição de densidade de estocagem e o uso consciente de antiparasitários são alguns dos aspectos a considerar.

\section{Agradecimentos}

Agradecemos pela bolsa de iniciação científica PROPESQ-BIC/UFRGS.

\section{Referências}

AIUB, J. A. Fitotratamento de efluente de aquacultura com Azolla filiculoides. 2006. Dissertação (Mestrado em Agronomia) - Faculdade de Agronomia. Universidade Federal do Rio Grande do Sul, Porto Alegre.

AOYAMA, K.; TOMITA, B.; CHAYA, K.; SAITO, $\mathrm{M}$., Isolation and geosmin production of bacteria-free Anabaena macrospora. Eisei Kagaku, Tokyo, v. 37, n. 2, p. 132-136, 1991.

BAFFORD, R. A.; SEAGULL, R. W.; CHUNG, SI-Y.; MILLIE, D. F. Intracellullar localization of the taste/odor metabolite, 2-methylisoborneol, in Oscillatoria limosa (cyanophyta). J. Phycol., Lawrence, v. 28, n. 3, 11-15, 1992.

BERGLIND, L.; JOHNSEN, I. J.; ORMEROD, K.; SKULBERG, O. M. Oscillatoria brevis (Kutz.) and some other especially odoriferousbenthic cyanophytes in Norwegian inland waters. Water Sci. Technol., Oxford, v. 15, n. 6-7, p. 241-246, 1983.

BIATO, D. O. Detecção e controle de off-flavor em tilápia de Nilo (Oreochromis niloticus), por meio de depuração e defumação. 2005. Dissertação (Mestrado em Ciências Biológicas) - Escola Superior de Agricultura Luiz de Queiroz. Universidade de São Paulo, São Paulo.

BOYD, C. Water quality in warmwater fish ponds. Alabama: Auburn University, 1981. 359 p.

BOWMER, K. H.; PADOVAN, A.; OLIVER, R. L.; KORTH, W.; GANF, G. G. Physiology of geosmin production by Anabaena circinalis isolated from the Murrumbidgee River, Australia. Water Sci. Technol, Oxford, v. 25, n. 2, p. 259-267, 1992.

BUTTERY, R. G.; GUADAGNY, D. G.; LING, L. C.; SEIFERT, R. M. Geosmin, a musty off-flavor of dry beans. Journal of Agricultural and Food Chemistry, Reading, v. 24, p. 419-420, 1976.

CONTE, E. D.; SHEN, C.; PERSCHBACKER, P. $\mathrm{W}$; MILLER, D. W. Determination of geosmin and methylisoborneol in catfish tissue (Ictalurus puncatatus) by micro-wave assisted distillation - solid phase adsorbent trapping. Journal of Agricultural and Food Chemistry, Reading, v. 44, p. 829-835, 1996.

CYBIS, L. F.; BENDATI, M. M.; MAIZONAVE, C. R. M.; WERNER, V. R.; DOMINGUES, C. D. (Ed.). 
Manual para estudo de cianobactérias planctônicas em mananciais de abastecimento público: caso da represa Lomba do Sabão e Lago Guaíba, Porto Alegre, Rio Grande do Sul. Rio de Janeiro: ABES, 2006. 64 p.

DIONIGI, C. P. Evaluation of geosmin and 2-methylisoborneol on the histidine dependence of TA98 and TA100 Salmonella typhimurium tester strains. Water Research, New York, v. 27, p. 1615-1618, 1993.

DIONIGI, C. P.; BETT, K. Variation in channel catfish Ictalurus punctatus flavor quality and its quality control implications. Journal of the World Aquaculture Society, Baton Rouge, v. 29, n. 2, p. 140-154, 1998.

DIONIGI, C. P.; CHAMPAGNE, E. T. Copper-containing aquaticherbicides increase geosmin biosynthesis by Streptomyces tendae and Penicillium expansum. Weed Sci, Champaign, v. 43, n. 2, p, 196-200, 1995.

ENGLE, C. R.; POUNDS, E. L.; van der PLOEG, M. The cost of off-flavor. Journal of the World Aquaculture Society, Baton Rouge, v. 26, p. 297-306, 1995.

FALCONER, L. F.; BARTRAM, J.; CHORUS, I.; KUIPER-GOODMAN, T. H.; BURCH, M.; CODD, G. A. Safe levels and safe practices. In: CHORUS I.; BARTRAM, J. (Ed.). Toxic cianobactérias in water: a guide to their public health- consequences, monitoring and management. London: E\&FN Spon, 1999. cap. 5, p. $155-178$

FROM, J.; HORLYCK, V. Sites of uptake of geosmin, a cause of earthy-flavor, in rainbow-trout (Salmogairdneri). Canadian Jounal of Fisheries and Aquatic Sciences, Toronto, v. 41, n. 8, p. 1224-1226, 1984.

GAUTIER, D.; BOYD, C. E.; LOVELL, R. T. Sampling channel catfish ponds for pre-harvest off-flavor detection. Aquaculture Engineering, Amsterdam, v. 26, n. 3, p. 205-213, 2002.

GERBER, N. N. Odorous substances from actinomycetes. Dev. Ind. Microbiol., Arlington, v. 20, n. 4, p. 225-238, 1979.

GRIMM, C. C.; LLOYD, S. W.; ZIMBA, P. V. Instrumental versus sensory detection of off-flavors in farm-raised channel catfish. Aquaculture, Amsterdam, v. 236, n. 2, p. 309-319, 2004.

GUST, B. PCR targeted Streptomyces gene replacement identifies a protein domain needed for biosynthesis of the sesquiterpene soil odor geosmin. Proceedings of the National Academy of Sciences, Washington, v. 100, n. 4, p. 1541-1546, 2003.

GUTTMAN, L.; RIJN, J. V. Identification of conditions underlying production of geosmina and 2-methylisoborneol in a recirculating system. Aquaculture, Amsterdam, v. 279, n. 3, p. 85-91, 2008.
HOWGATE, P. Tainting of farmed fish by geosmina and 2-methyl-isoborneol: a review of sensory aspects and of uptake/depuration. Aquaculture, Amsterdam, v. 234, n. 2, p. 155-181, 2004.

HOSON, T. Growth characteristics of the musty odor producing alga, Oscillatoria tenuis, Water Sci. Technol., Oxford, v. 25, n. 2, p. 177-184, 1992.

INTERNATIONAL ORGANIZATION FOR STANDARDIZATION. ISO 13301: Sensory analysismethodology-general guidance for measuring odour, flavour and taste detection thresholds by a three-alternative forced-choice (3-AFC) procedure. International Organization for Standardization, Geneva, Switzerland, 2002.

IREDALE, D. G.; RIGBY, D. Effect of smock processing on muddy odor and taste in rainbow trout (Salmo gairdner). Journal of the Fisheries Research Board of Canada, Toronto, v. 29, n. 9, p. 65-66, 1972.

IZAGUIRRE, G.; HWANG, C. J.; KRASNER, S. W.; MCGUIRE, M. J. Production of 2-methylisoborneol by two benthic cyanophyta. Water Sci. Technol., Oxford, v. 15, n. 6-7, p. 211-220, 1983.

JOHNSEN, P. B.; LLOYD, S. W. Influence of fat content on uptake e depuration of the off-flavor 2-methylisoborneol by channel catfish (ictalarus punctatus). Canadian Journal of Fisheries and Aquatic Sciences, Toronto, v. 49, n. 8, p. 2406-2411, 1992.

JOHNSEN, P. B.; KELLY, C. A. A technique for the quantitative sensory evaluation of farm raised catfish. Journal of Sensory Studies, Scottsdale, v. 4, n. 5, p. 189199, 1990.

JÜTTNER, F.; HOEFLACHER, B.; WURSTER, $\mathrm{K}$. Seasonal analysis of volatile organic biogenic substances (VOBS) in freshwaterphytoplankton populations dominated by Dinobryon, Microcystisand Aphanizomenon. J. Phycol., Lawrence, v. 22, n. 2, p. 169-175, 1986.

KUBITZA, F. Qualidade de água no cultivo de peixes e camarões. Jundiaí: Degaspari, 2003. 1v.

Tilápia: tecnologia e planejamento na produção comercial. São Paulo: Degaspari, 2000. 1v.

LAZDUNSKI, A. M.; VENTRE, I.; STURGIS, J. N. Regulatory circuits and communication in gram-negative bacteria. Nat.Rev.Microbiology, London, v. 2, n. 7, p. 581-592, 2004

LELANA, I. Y. B. Geosmin and off-flavor in channel catfish. 1987. (PhD) Thesis (Doctor in Sciences) Auburn University, Alabama. 
LIND, O. T.; KATZIF, S. D. Nitrogen and the threshold odor number produced by an actinomycete isolated from lake sediments. Water Sci. Technol., Oxford, v. 20, n. 1, p. 8-9, 1988.

LLOYD, S. W.; GRIMM, C. C. Analysis of 2-Methylisoborneol and Geosmin in Catfish by Microwave Distillation-Solid-Phase Microextraction. Journal of Agricultural and Food Chemistry, Davis, v. 47, n. 1, p. 164-169, 1999.

LOVELL, R. T.; LELANA, I. Y.; BOYD, C. E.; ARMSTRONG, M. S. Geosmin and musty-muddy flavors in pond-raised channelcatfish. Trans. Am. Fish. Soc., Bethesda, v. 115, n. 4, p. 485-489, 1986.

LOVELL, R. T. New off-flavors in pond-cultured channel catfish. Aquaculture, Amsterdam, v. 30, n. 3, p. 329-334, 1983.

MABÍLIA, R. G.; SOUZA, S. M. G. de. Efeito do tratamento com diflubenzuron na hematologia de jundiás, Rhandia quelen infestados por Lernaea cyprinacea (copepoda) em banhos de imersão de 24 horas. Acta Scientiarum: Biological Sciences, Maringá, v. 28, n. 2, p. 159-163, 2006.

MATSUMOTO, A.; TSUCHIYA, Y. Earthy-musty odorproducing cyanophytes isolated from five water areas in Tokyo. Water Sci. Technol., Oxford, v. 20, n. 8-9, p. 179183, 1988.

MARTIN, J. F.; IZAGUIRRE, G.; WATERSTRAT, P. A planctonic Oscillatoria species from Mississippi catfish ponds that produces the off-flavor coupond 2-methylisoborneol. Water Research, New York, v. 9, n. 5, p. 1447-1451, 1991.

MARTIN, J. F.; McCOY, C. P.; GRENLEAF, W.; BENNETT, L. Analysis of 2-methylisoborneol in water, mud and channel catfish (Ictalurus punctatus) from commercial culture ponds in Mississippi. Can. J. Fish. Aquat. Sci., Toronto, v. 44, n. 3, p. 909-912, 1987.

NEGORO, T.; ANDO, M.; ICHIKAWA, N. Blue-green algae in lake Biwa which produce earthy-musty odors. Water Sci. Technol., Oxford, v. 20, n. 8-9, p. 117-123, 1988.

OLSON, T. D.; WEIRICH, C. R.; GRIMM, C. C. Seasonal trends in 2-methylisoborneol levels of fresh and brackish water channel catfish Ictalurus punctatus ponds. In: World Aquaculture Society. (Ed.). Processings of Aquaculture, Lake Buena Vista: W.A.S, 2001. p. 495.

PARK, G.; YU, M.; KIM, E.; KIM, H. Comparison between ozone and ferrate in oxidizing geosmin and 2-MIB in water. Water Science and Technology, London, v. 55, n. 5, p. 117-25, 2007.
PEARL, H. W.; TUCKER, C. S. Ecology of blue-green algae in aquaculture ponds. Journal of World Aquaculture Society, Baton Rouge, v. 26, n. 2, p. 109-131, 1995.

PERCIVAL, S.; DRABSCH, P.; GLENCROSS, B. Determining factors affecting muddy-flavor taint in farmed barramundi, Lates calcarifer. Aquaculture, Amsterdam, v. 28, n. 4, p. 136-143, 2008.

PERSSON, P. E. 19th century and early 20th century studies on aquatic off-flavor - a historical perspective. Water Science and Technology, London, v. 31, n. 11, p. 9-13, 1995.

. Notes on muddy flavor. IV. Variability of sensory response to 2-methylisoborneol. Aqua Fennica, Helsink, v. 9, n. 2, p. 48-52, 1979.

PRICE, N. M.; MOREL, F. M. M. Trace metal nutrition and toxicity in phytoplankton. Arch. Hydrobiol, Sttutgart, v. 42, n. 1, p. 79-97, 1994.

ROBIN, J.; CRAVEDI, J. P.; HILLENWECK, A.; DESHAYES, C.; VALLOD, D. Off flavor characterization and origin in French trout farming. Aquaculture, Amsterdam, v. 260, n. 3, p. 128-138, 2006.

ROSEN, B. H.; MCLEOD, B. W.; SIMPSON, M. $\mathrm{R}$. Accumulation and release of geosmin during the growth phases of Anabaena circinalis (Kutz.). Water Sci. Technol., Oxford, v. 25, n. 2, p. 185-190, 1992.

SCHRADER, K. K.; DE REGT, M. Q.; TIDWELL, P. D.; TUCKER, C. S.; DUKE, S. O. Compounds with selective toxicity towards the off-flavor metaboliteproducing cyanobacterium Oscillatoria cf. chalybea. Aquaculture, Amsterdam, v. 163, n. 1-2, p. 85-99, 1988.

SCHRADER, K. K.; BLEVINS, W. T. Geosminproducing species of Streptomyces and Lyngbya from aquaculture ponds. Can. J. Microbiol., Ottawa, v. 39, n. 9, p. 834-840, 1993.

SCHRADER, K. K.; BLEVINS, W. T. Geosmin producing species of Streptoyces and Lyngbya from aquaculture ponds. Can. J. Microbiol. Ottawa, v. 39, n. 9, p. 834-840, 1993.

SMITH, J. L.; BOYER, G. L.; ZIMBA, P. V. A review of cyanobacterial odorous and bioactive metabolites: Impacts and management alternatives in aquaculture. Aquaculture, Amsterdam, v. 280, n. 1-4, p. 5-20, 2008.

SONG, W. Ultrasonically induced degradation of 2-methylisoborneol and geosmin. Water Research, Lyngby, v. 41, n. 12, p. 2672-2678, 2007.

SOUZA, S. M. G. de; EBERT, A.; GODOY, L. C.; OLIVEIRA, D. Análise de off-flavor em filés de Tilápia do Nilo (Oreochromis niloticus) cultivadas em sistema de recirculação e sistema aberto. In: REUNIÃO ANUAL 
DA SOCIEDADE BRASILEIRA DE ZOOTECNIA, 47. 2010, Salvador. Anais... Salvador: Empreendedorismo e Progressos Científicos na Zootecnia Brasileira de Vanguarda, 2010. p. 63-64.

SUGIURA, N.; INAMORI, Y.; HOSAKA, Y.; SUDO, R.; TAKAHASHI, G. Algae enhancing musty odor production by actinomycetes in Lake Kasumigaura. Hydrobiology, Dordrect, v. 288, n. 1, p. 57-64, 1994.

TORLONI, C. E. C. Eliminação do sabor e odor desagradáveis em tilápias do Nilo (Sarotherodon niloticus) pelo processo de depuração. Ciência e Cultura, Campinas, v. 34, n. 5, p. 657-663, 1983.

TSUCHIYA, Y; MATSUMOTO, A. Identification of volatile metabolites produced by blue-green algae. Water Sci. Technol., Oxford, v. 20, n. 8-9, p. 149-155, 1988.

TSUCHIYA, Y.; MATSUMOTO, A.; OKAMOTO, T. Volatile metabolites produced by actinomycetes, isolated from Lake Tairo at Miyakejima. J. Pharm. Soc. Jpn., Tokyo, v. 98, n. 4, p. 545-550, 1978.

TURCHINI, G. M.; MORETT, V. M.; MENTASI, T.; ORBAN, E.; VALFRÈ, F. Effects of dietary lipid source on fillet chemical composition, flavour volatile compounds and sensory characteristics in the freshwater fish tench (Tinca tinca L.). Food Chemistry, Reading, v. 102, n. 3, p. 1144-1155, 2007.

TUCKER, S. Off-flavor problems in aquaculture. Reviews in Fisheries Science, Philadelphia, v. 8, n. 1, p. 45-88, 2000.

UTKILEN, H. C.; FROESHAUG, M. Geosmin production and excretion in a planktonic and benthic Oscillatoria. Water Sci. Technol, Oxford, v. 25, n. 2, p. 199-206, 1992.

VALLOD, D.; CRAVEDY, J. P.; HILLENWECK, A.; ROBIN, J. Analysis off the off-flavor risk in carp production in ponds in Dombes and Forez (France). Aquacult. Int., Dordrechet, v. 15, n. 4, p. 287-298, 2007.

VAN DER PLOEG, M.; TUCKER, C. S.; BOYD, C. E. Geosmin and 2-methylisoborneol production by cyanobacteria in fish ponds in the south-eastern United States. Water Sci. Technol, Oxford, v. 25, n. 2, p. 283290, 1992.
VAN DER PLOEG, M.; TUCKER, C. S. Seasonal trends in flavorquality of channel catfish, Ictalurus punctatus, from commercialponds in Mississippi. J. Appl. Aquac., Binghamton, v. 3, n. 1-2, p. 121-140, 1993.

VAN DER PLOEG, M.; DENNIS, M. E.; DE REGT, M. Q. Biology of Oscillatoria cf. chalybea, a 2-methylisoborneol producing bluegreenalga of Mississippi catfish ponds. Water Sci. Technol, Oxford, v. 31, n. 11, p. 173-180, 1995.

WANKE, M.; SKORUPINSKA-TUDEK, K.; SWIEZEWSKA, E. Isoprenoid biosynthesis via 1-deoxyD-xylulose 5-phosphate/2-C-methyl- D-erytritol 4-phosphate (DOXP/MEP) pathway. Acta Biochimica Polonica, Warsaw, v. 48, n. 3, p. 663-672, 2001.

WATSON, S. B.; RIDAL, J. Periphyton: a primary source of widespread and severe taste and odour. Water Science and Technology, Oxford, v. 49, n. 9, p. 33-39, 2004.

WOOD, S.; WILLIAMS, S. T.; WHITE, W. R. Potential sites of geosmin production by streptomycetes in and around reservoirs. J. Appl. Bacteriol, Davis, v. 58, n. 3, p. 319-326, 1985.

WU, J. T.; MA, P. I.; CHOU, T. L. Variation of geosmin content in Anabaena cells and its relation to nitrogen utilization. Arch. Microbiol, Carbondale, v. 157, n. 1, p. 66-76, 1991.

XU, L.; XIONG, B.; PAN, Y.; WANG, J.; CAO, H.; ZHAO, W. Relationship between concentrations of odorous compounds and biomass of phytoplankton and actinomycetes in freshwater ponds of Beijing, China. Aquacult Int, Dordrechet, v. 18, n. 2, p. 245-254, 2010.

YU, F. G.; SOUZA, S. M. G de. Offflavor em aquicultura. 2007. Trabalho (Graduação em Farmácia) - Faculdade de Farmácia. Universidade Federal do Rio Grande do Sul, Porto Alegre.

YURKOWSKI, M.; TABACHEK, J. L. Identification, analysis, and removal of geosmin frommuddy-flavored trout. Journal of the Fisheries Research Board of Canada, Toronto, v. 31, n. 9, p. 1851-1858, 1974.

ZAITLINA, B.; WATSON, S. Actinomycetes in relation to taste and odour in drinking water: myths, tenets and truths. Water Research, New York, v. 40, n. 6, p. 17411753, 2006. 